There is a detailed preliminary section on the uniform histological classification of breast cancer which is used in this study and this is followed by careful world-wide reports. These are summarized at the end by exhaustive tables of incidence rates for cancer of the breast classified by histological type in the different geographical locations.

The format is a paperback typescript but the production, diagrams and microphotographs are clear. There is a detailed bibliography. This monograph will prove useful to the specialist pathologists and epidemiologists concerned with this important malignancy.

\section{Intravenous Anaesthetic Agents}

By J. W. Dundee. Current Topics in Anaesthesia series. No. 1. Edited by S. A. Feldman and C. F. Scurr. Pp. 160, Illustrated. Edward Arnold, London, 1979. £9.25.

This is the first in a series on current topics in anaesthesia. The aim of the series, as explained by the general editors in their preface, is to help readers to keep up to date with current literature. Each number of the series is intended to be an authoritative, concise and topical review of a subject, made more digestible by having only key references and avoiding treatment in depth.

The author of the present volume is without doubt the best known and most respected authority in this field. It is disappointing to find that the book strays considerably from the brief laid down for the series. A major reason for this must be the long gestation period between writing and publication - of much greater import in this sort of work than in a traditional textbook or monograph. Written between January and March 1978, dealing with times topical in that trimester, and published some 18 months later, it of necessity lacks a topical flavour and has in many parts been overtaken by events. The effects of the hurried writing, for which Professor Dundee apologizes, are obvious. Many chapters lack cohesion and balance, especially those to which others have contributed. One chapter has a completely different reference system from the remainder. Among the shortest chapters is that devoted to the barbiturates - surprising in view of the widespread use of this class of drugs. The length of the chapters devoted to ketamine, althesin and etomidate reflects the author's personal current interests but may mislead readers as to the importance and place of these agents. The detailed listing of the results of clinical trials of these drugs is out of place in a work such as this. The mechanisms of hypersensitivity reactions have become better understood since this work was written. The 5 tables listing reported reactions and the 8 pages of references in the chapter on this topic are hardly in accord with the intentions of this series.

In spite of these criticisms there is much of interest in this book. The short pastiche personal assessments at the end of most chapters help to restore some balance to the contents. The delay in publication means that some currently topical themes - minaxolone, for example, and the possible protective effects of barbiturates against hypoxia - are not mentioned. Such omissions are unavoidable when producing a work devoted to a field in which so much interest currently prevails. However, these omissions and the high price of the book do not commend it as this week's bargain buy.

\section{Introduction to Physiology}

Vol. 4. By Hugh Davson and M. B. Segal. Pp. xii +621 , Illustrated. Academic Press, London; Grune \& Stratton, New York, 1978. $£ 11.80$.

This fourth volume of Davson and Segal's textbook, which covers the control of movement and posture is ambitious in its scope. It attempts both to explain basic mechanisms and to provide a comprehensive, up-to-date review of recent research. However, the conflict between the need to simplify for the basic explanations and yet to provide a comprehensive review leads to a confused and sometimes contradictory text. Although many individual topics are well explained there is, especially for the more recent results, a lack of both the properly critical approach and in some cases the awareness of the appropriate historical context that should be provided by the type of review that the authors are attempting. Moreover, in many places the book is sloppily written. For instance we are told (correctly) on p. 415 that the effects of the Purkinje cells of the cerebellum are entirely inhibitory, but p. 385 refers to their 'excitatory or inhibitory activities' and p. 30 refers to synaptic boutons on Purkinje cells as being 'entirely inhibitory'.

Thus it would be hard to recommend this book unequivocally as either a student textbook or as a specialist review. However, its long list of supporting references can usefully serve as an introduction to many topics in motor control physiology so long as the reader then relies on his or her own judgements of the original material in addition to those provided here.

\section{Liver Disorders in Childhood}

Alex P. Mowat. Postgraduate Paediatrics series-Gen. Editor J. Apley. Pp.x ii +407 illustrated. Butterworths, London, 1979. $£ 18 \cdot 50$.

This is an important book, which attempts to fill a hiatus that has existed for a long time in both the paediatric and hepatological literature. To a large extent it succeeds, for the author Alex Mowat, Consultant Paediatrician at Kings College Hospital, London, is uniquely qualified to accomplish this task.

The stated aim of the book is to provide a comprehensive and up-to-date account of liver and biliary disorders in childhood for the practising clinician. It begins with a clinically orientated description of the anatomy and physiology of the liver and bile ducts and describes well the frequent congenital anatomical variations that are encountered. Lucid accounts of both unconjugated and conjugated hyperbilirubinaemia in the neonatal period follow and the section dealing with the investigation and management of suspected biliary atresia is particularly impressive.

By contrast the chapter dealing with acute hepatitis was disappointing with too much emphasis placed on recent research into pathogenesis. An important problem, namely the management of an infant born to a mother who is a chronic carrier of the hepatitis B surface antigen is not dealt with at all. Should one or should one not ever use hyperimmune globulin and if so, when? Similarly the chapter on chronic hepatitis is marred by the inclusion of speculative immunology which leaves the reader confused rather than enlightened. These, however, are minor criticisms and the rest of the book maintains a consistently high standard.

At the end of each chapter can be found a short but comprehensive bibliography, with some of the cited references as recent as 1978 .

For the hepatologist the book is noteworthy for the omission of any reference to alchoholic liver disease! It certainly deserves a place in any hepatologist's library as well as that of the paediatrician with an interest in gastroenterological disorders, and at $£ 18.50$ the price is not excessive.

\section{Stomach Cancer}

Workshops on the Biology of Human Cancer. UICC Technical Report Series. Vol. 34. Edited by D. W. PIPER. Pp. viii +138 , Illustrated. International Union against Cancer, Geneva. 1978. Sw.fr.15.00.

Cancer of the stomach is responsible for about one in 5 of all cancer deaths in the Western World and in some high-risk areas, Japan for example, this rises to about $50 \%$ of deaths from malignant disease. The poor results of therapy have 
engendered enormous efforts on behalf of both laboratory and clinical investigators into the possibilities of earlier diagnosis or, better still, prevention of this disease.

This report presents the proceedings of a Workshop on stomach cancer held in Geneva in April 1977 under the auspices of the International Union against Cancer. Ateam of 4 Japanese, 4 Americans and one Canadian, Austrian, Australian and Finnish experts, including pathologists, epidemiologists, biochemists and clinicians, contribute to the study. The topics range over epidemiology, pre-malignant changes in the gastric mucosa, early gastric cancer, biø⿺辶一 chemical immunological changes in the affected stomach, the study of animal models of gastric cancer and the possibilitie? of early detection and of prevention.

The production is in paper-back typescript, but both tex and diagrams are commendably clear. The bibliography is detailed and includes references up to 1977. This is certainly: a monograph which should be consulted by clinicians an laboratory workers with an interest in the field of gastro-? intestinal malignant disease.

\section{Notice}

The Twenty-first Postgraduate Institute for Pathologists' Course in Clinical Cytopathology is to be given at The Johns Hopkins University School of Medicine and The Johns Hopkins Hospital, Baltimore, Maryland, 14-25 April, 1980. The full 2-week programme is designed for Pathologists who are certified (or qualified) by the American Board of Pathology (PA), or their international equivalents.

Topics will be covered in lectures, explored in small informal conferences, and discussed over the microscope with the Faculty. Self-instructional material will be available to augment at individual pace. A loan set of slides with text will be sent to each participant for homestudy during March and April before the Institute. Credit hours 120 in AMA Category 1.

Application is to made before 7 March, 1980. For details, write: John K. Frost, M.D., 610 Pathology Building, The Johns Hopkins Hospital, Baltimore, Maryland 21205, U.S.A. 